\title{
SATUA TJAI TJENIK \\ (PENDIDIKAN AGAMA HINDU YANG TERSELUBUNG)
}

\author{
I Made Arsa Wiguna
}

Institut Agama Hindu Negeri Tampung Penyang Palangkaraya

bawiayahfda@gmail.com

\begin{abstract}
Riwayat Jurnal
Artikel diterima :-

Artikel direvisi : :

Artikel disetujui :-
\end{abstract}

\begin{abstract}
Abstrak
Tulisan ini merupakan salah satu sub tema dari hasil penelitian tentang satua-satua Bali. Pendidikan Agama Hindu dalam satua Tjai Tjenik ini digambarkan dalam beberapa kejadian dan tokoh. Ajaran Guru Susrusa, Karma, Catur Paramita, Dama dan Arjawa secara implisit mengalir dalam percakapan para tokoh dan kejadian di dalamnya. Satua Tjai Tjenik dan juga satua Bali lainnya hendaknya dapat dijadikan sebagai media pendidikan agama Hindu agar terwujud generasi muda Hindu yang religius dan berkarakter mulia.
\end{abstract}

Kata Kunci: Satua Tjai Tjenik, Pendidikan Agama Hindu.

\section{PENDAhUluAN}

Cerita rakyat adalah salah satu media penting bagi pendidikan, dan masing-masing daerah memiliki cerita rakyatnya tersendiri. Sejalan dengan hal itu, Rampan (2014: 15) menjelaskan ada beberapa jenis cerita rakyat yang hidup dalam lingkungan penutur di dalam sejumlah masyarakat tertentu. Jenis-jenis itu lahir dan hidup dalam masyarakat, dan keberadaannya ditentukan oleh dua hal. Pertama cerita rakyat yang dibawa oleh orang-orang tertentu seperti musafir, pedagang, penyebar agama, serdadu, dan lain-lain yang datang dari sumber-sumber cerita rakyat seperti Mesir Kuno, Yunani Kuno, Maya, Romawi, Aztec, dan sebagainya. Kedua, lahirnya orang-orang cerdik cendekiawan yang mampu mengembangkan kreativitas mereka di dalam suatu daerah tertentu, lalu menciptakan kearifan lokal di daerahnya berupa kisah-kisah yang memikat. Rampan menambahkan kombinasi kedua hal itu melahirkan berbagai jenis cerita rakyat diantaranya adalah dongeng dan fabel.Dongeng ceritanya bersifat fiktif, ceritanya diangkat dari khasanah masa silam tentang tokoh-tokoh manusia atau makluk lainnya yang dibuat sama seperti manusia beraktivitas dalam kehidupan sehari-hari. Sedangkan fabel yakni cerita rakyat yang berkisah tentang binatang, para binatang hidup dan beraktivitas 
seperti manusia. Satua identik dengan dongeng, dan fabel.

Satua merupakan salah satu sastra lisan yang hidup dan berkembang di Bali. Dulunya satua hanya digunakan untuk menemani anak tidur, tetapi semakin lama, satua justru diminati karena nilai-nilai yang ada di dalamnya dapat dijadikan sebagai media bagi orang tua untuk mendidik anak mereka.

Suastika (2011: 1-2) menyatakan bahwa dalam tradisi masatua ini peranan orangtua, yaitu ayah, ibu, kakek nenek sangatlah penting melakukan usaha berupa menyampaikan cerita lisan ini dengan terus menerus sebagai milik bersama di waktu malam ketika akan menidurkan anak-anak dan cucunya. Suastika menambahkan bahwa penting untuk diketahui dalam kesadaran anak seperti inilah nilai pendidikan, agama, budi pekerti, kemanusiaan akan tumbuh secara dini sebagai dasar pembentukan karakter dan moral anak. Satua merupakan cerita lisan berbentuk prosa yang disampaikan secara bebas, dengan menggunakan bahasa Bali kapara (lumrah) yang secara umum dikenal oleh masyarakat Bali dan tidak ada ikatan yang jelas seperti dalam puisi Bali yang disebut gaguritan (Suastika, 2011: 15). Lebih lanjut menurut Suastika satua juga memiliki kebebasan dalam pengungkapannya, seperti adanya kalimat narasi yang panjang dan pendek sesuai kebutuhan alur cerita, baik itu berupa kalimat tanya, adanya dialog berulang-ulang antar tokohnya, ada kata penanda untuk mempercepat alur dan ada bagian simpulan atau cerita selesai seperti misalnya "asapunika, satuane puput". Jika dilihat jenis ceritanya, satua dapat dibagi menjadi: 1) satua/dongeng biasa yaitu pelakunya manusia; 2) fabel yang menceritakan kehidupan binatang; 3) anekdot yang mengemas sindiran dalam bentuk cerita; 4) Lelucon yang banyak bercerita tentang hal-hal lucu yang dilakukan tokoh di dalmnya; 5) etiologis yang mendekati pengertian filosofis, dalam artian cerita yang disampaikan mengandung ajaran filosofis, atau asalusul sesuatu hal; dan 6 healing stories merupakan satua atau dongeng yang banyak bercerita tentang semangat dan kerja keras yang dapat memotivasi. Satua Tjai Tjenik ini jika dilihat dari jenisnya, termasuk ke dalam jenis satua biasa (pelakunya manusia dan juga binatang/fabel), lelucon, dan etiologis (sejarah pohon bambu tultul). Selengkapnya akan diulas dalam pembahasan.

\section{PEMBAHASAN}

Tidak semua satua yang telah dituliskan kembali memiliki popularitas di kalangan masyarakat Bali, meskipun pada dasarnya terdapat nilai-nilai moral dan budi pekerti dalam satua tersebut. Satua tidak hanya menawarkan nilai-nilai hedonis yang bersifat menghibur semata namun juga terdapat unsur pendidikan agama Hindu di dalamnya yang secara implisit digambarkan dalam penokohan dan kejadian dalam satua tersebut.

Untuk mengenalkan kembali satua-satua beserta nilai dan unsur pendidikan agama Hindu tersebut, perlu 
usaha konkret salah satunya melalui kajian satua yang berjudul "Tjai Tjenik" ini. Adapun kutipannya sebagai berikut:

Katjarita Pan Bekung ngelah panak duduk-dudukan adiri. Panakne ento sing kone ngelah adan, nanging jan bapanne ngaukin panaka tuah kaukina "Tjai Tjnik" dogen.

Djani makiren bapanne mati, mabesen kone ia teken panakne, kene pabesenne: "Ih, Tjai Tjenik, tjai suba nawang bapa gelem sanget, mirib bapa enggal ngalahin tjai mati. Nah dimatin bapane, jan suba bapa matanem, eda pesan tjai nu ngojong dini, gediang iban tjaine uli dini. Jan tjai nu ngojong dini, pedas liu anake malagendahang tjai. Asing teka lakara ada njagurin, ada njontokin tendas tjaine. Masaut panakne: "Bapa nunden itjang magedi uli dini, men kidja lakun itjang ngojong?" "Nah keme laku sig anake takutina teken djalmane, keto kone pabesen bapanne. Disuban bapanne mati, makeneh-keneh kone Tjai Tjenik : "Didja laku djani ngojong. Ah, lakar kema djani laku mamarekan sig Anake Agung. Njen ja bani teken Anak Agung".

Katjarita djani dipuri kone ia lakar mamarekan. Sedek dina anu Ida Anake Agung katangkilin baan baudandan Idane. Sesek djedjel kone didjabaan. Nah, djani dadi ngatudju pesan Tjai Tjenik madengokan uli kurine, laut ia ningalin anak liu pesan. Ditu ia djedjeh pesan, lantas ia kauk-kauk ngidih tulung. Teka lantas parekan nakonin Tjai Tjenik. Tjai Tjenik ngorahang ibanne takut, tur ia nuturang pabesen bapanne. Suud ia nutur, masaut lantas parekanne : "Nah lamun keto, keme laku to, beneng kanginang dogen, njanan dong nepukin ia tjai anak tuara taen paaakin djelma. Jen suba tjai neked ditu, pedas tjai rahaju:. Mara keto abet parekane, lantas Tjai Tjenik magedi uli puri.

Katjarita padjalan Tjai Tjenik djani, suba kone teked dialase wajah, laut ia nepukin matjan lakar njarap tjeleng. Makeneh-keneh lantas Tjai Tjenik: "Nah ne apa ada anak. Meh ne djenenga ane orahanga tusing baninin djelma. Lakar alih kone djani ia keme”.

Katjarita djani i matjan, mara ia ukana njarap $i$ tjeleng, lantas ketigina teken Tjai Tjenik. Tangkedjut lantas $i$ matjan, laut ia matolihan. Mara nota ada djelma teka, laut ia ngomong ; "Ih Tjai Tjenik, ngenken tjai mai tjelapat-tjelapat padidian katengah alase?" Keme mulih me, njanan kamah tendasne”. Masaut Tjai Tjenik: "Ah, awak sing njak mulih”. Ping kuda-kuda kaden suba Tjai Tjenik tundungina teken i matjan, masih ia tusing njak magedi. I matjan lantas ngalautang padjalanne, tur tutuga teken Tjai Tjenik.

Sasubanne djoh padjalanne $i$ matjan teken Tjai Tjenik, nepukin lantas ia padukuhan. I matjan lantas ngaukin Djero Dukuh : "Djero Dukuh, Djero Dukuh". "Njen ento kauk-kauk diwangan? Itjang $i$ mantjan, keto pasautne $i$ matjan. Djero Dukuh lantas pesu, tur matakon teken $i$ matjan. "Ih matjan, ngenken iba tumben mai?" Masaut i matjan: "Kene ke Dukuh. Ne ada anak tjenik nutug itjang ileh-ileh. Kidja dja laku masih bareng dogen ia nutug, kanti itjang tusing taen maan 
amah-amahan. Mara ukana maan kidang ketigina lantas. Malaib burone makedjang ane ukana sarap itjang. Tunden mulihne masih tusing ia njak. Djani djerone dja suba ngadjak ia dini nah!” Ngandika djero Dukuh: "Nah keto dja keneh tjaine, awake suba ngadjak ia dini". Lantas kaukina Tjai Tjenik teken i matjan, laut ia ngomong: "Tjai Tjenik, nah djani dini tjai ngojong iring djero Dukuh. Kenken dja pangandikan djero Dukuhe tuutang dogen abete. Da tjai tra nuutang!" "Nah, keto kone pasautne Tjai Tjenik. Suba suud keto, magedi lantas i matjan.

Katjarita djani Tjai Tjenik ditu ia mamarekan sig djero Dukuhe. Sedek dina anu matakon kone djero Dukuh teken Tjai Tjenik: "Tjai Tjenik, njen adan tjaine, muah didja umahe?" Tjai Tjenik inget ia teken pabesen i matjane, nunden nuutang dogen pangandikan djero Dukuhe, lantas ia masaut : "Ih Tjai Tjenik, njen adan tjaine muah didja umahe?" Makajunkajun lantas djero Dukuh : "Ah,kamulan djenenga ia keto, nuut nuutang dogen.

Sedek djero Dukuh mapuja, Tjai Tjenik nikaanga njemak pasepan teken pawadjikan. Kene pangandikanne ; "Tjai Tjenik, djemakang awake pasepane teken pawadjikane!" Tjai Tjenik nuutang kone pangadikan djero Dukuhe buka keto : "Tjai Tjenik, djemakang awake pasepane teken pawadjikane!" Disuban djero Dukuhe munggah lakar maweda, djero Dukuh malinggih kone di balene. Tjai Tjenik beten kone ia negak dibabatarane. Njemak djero Dukuh genta, Tjai Tjenik papap-papak kone djemaka anggona nuutang djero Dukuh. Ngentungang djero
Dukuh skarura, ia aas-aasan bungane kone entung-entunganga. Keto dogen kone Tjai Tjenik ditu, nanging ke djero Dukuh tusing pesan taen menduin ia.

Djani ngangsan ngelihang kone Tjai Tjenik tur ngangsan ngaririhang dogen. Ngandika lantas djero Dukuh teken rabinne: "Biangne, jan akene undukne Tjai Tjenik dini, makelo-kelo lakar kalahanga tiang. Meh matianga katekan tiang. Djani lan suba belog-belog tendasne Tjai Tjenik, apanga ia mati. Jan depinin ia idup, keweh lakara tiang”. Ngandika rabine : "Inggih ledang pakajunan djerone kewanten. Daingan djerone patjang seda, ten betjikan sampun ipun pademang. Men mangkin, wireh asapunika pakajunan djerone, sapunapi antuk djerone?" "Ah, dengan baan beli ngenehang ento, biangne".

Suba suud keto, nikaina lantas Tjai Tjenik teken djero Dukuh. "Tjai Tjenik, mai dja malu, ada takonang bapa teken tjai abedik”. Njagdjag lantas Tjai Tjenik. Ngandika djero Dukuh ; "Tjai Tjenik, ne tjai kelan suba kelih dini adjak bapa, tjai tusing nelokin meme bapane?"

Matur Tjai Tjenik: "Inggih djero Dukuh, jan buat iseng tiange ring $i$ meme kalih $i$ bapa dong sampun kaliwat pisan. Samalihne tiang tan wenten pisan uning ring imeme, kantun tiang alit sampun kaonina padem ring i meme. Men mangkin asapunapi antuk tiang, mamanah nelokin anak sampun padem?" Ngandika djero Dukuh: "Ah ento sing elah pesan".

Katjarita paakan djeronne ada kone tiing alingseh, tur ngatudju pesan ada akatih paling tegeha, sat ilid kone 
muntjuk tiinge totonan. Ento lantas patudjuhina Tjai Tjenik teken djero Dukuh. "Tjai Tjenik, tingalin dja tiinge ane paling tegeha ento. Lamun tjai makeneh apang nepukin raraman tjaine, tiinge ento penek to, tepuk baan tjai ngalih meme bapan tjaine”. Baan legan kenehne Tjai Tjenik, lakar nepukin rarama tuara naan teken dewek kabelog-belog, ngenggalang lantas ia menek tiinge ento. Suba nganteg djene basa tengahane, makaukan lantas ia: "Djero Dukuh, djero Dukuh, nguda tonden tepuk nika raraman tiange?"Ngandika djero Dukuh uli beten : "Penekang te ibane buin, sing ia tepuk!" Buin kone ia angkod-angkod ngamenekang. Suba djoh pesan baduur kanti suba tjenik kone tingalina teken Tjai Tjenik djero Dukuh, buin kone ia kaukkauk: "Djero Dukuh, djero Dukuh, nguda tonden masih tepukin meme bapan tiange?" Ngandika djero Dukuh : "Begbed tjai kauk-kauk dogenan, penekang dogen te suba ibane buin abedik njanan sing ia tepukin tjai raraman tjaine!' Nganti suba ada djenenga nu buin adepa muntjuk tiinge masih sing kone ia nepukin njen-njen beduur. Olet-olet kone ia baduur. Djani angsehanga kone ia menek, ia mara neked dimuntjuk, ia ilang kone lantas Tjai Tjenik.

Katjarita padjalanne Tjai Tjenik, anak suba titah Widhi nunden ia buka keto, teked suba ia dikadituan, tur tepukina suba meme bapanne. Nah djani tjaritajang djero Dukuh, mara dane matolihan menek, sing kone ada Tjai Tjenik. Makajun-kajun kone dane : "Kidja ia lakuna anake tjenik ento jen ia ulung, nguda ia sing dingeh ada ulungan apa-apa dini. Bedh, aeng dja ririh anake tjenik ento, lakar penek dja tiinge totonan, apang tawang, kidja ia lakuna polonne. Ditu lantas djero Dukuh menek ditiinge totonan.

Katjarita suba nganteg basa tengahane, masih tusing kone tjingakina ada njen-njen. Buin kone ngamenekang djero Dukuh. Ja mara ukana djudjuha mutjuk tiinge, ompak lantas tur tebeka djitne djeroDukuh, getihne paseleet kone tuuta punjan tiinge. Seda lantas djero Dukuh.

Aketo katutranne, sangkan ada punjan tiing tultul, tur tiinge totonan sudra, sing dadi aba kasanggah.

Terjemahan:

Alkisah ada seorang pria bernama Pan Bekung. Ia memiliki seorang anak angkat. Anak itu tidak memiliki nama, tapi Pan Bekung memanggilnya dengan nama Tjai Tjenik.

Sekarang diceritakan bahwa umur ayahnya tidak lama lagi, dan sebelum meninggal, ayahnya berpesan seperti ini: "Tjai Tjenik, kamu sudah tau kalau ayah sakit keras dan mungkin sebentar lagi akan meninggalkanmu. Setelah ayah dikubur, jangan kamu tinggal disini lagi, kalau kamu masih tinggal disini, pastilah banyak orang yang mempermainkanmu, datang dan mungkin akan memukulimu." Anaknya lalu berkata "ayah menyuruh saya pergi, lalu dimana saya harus tinggal?" "Nah pergilah ke tempat orang yang ditakuti oleh banyak orang" begitu pesan ayahnya. Setelah ayahnya meninggal, Tjai Tjenik mulai berpikir 
"kemana saya harus pergi sekarang. Ah, kesana saja menjadi abdi di puri (kerajaan/kediaman) Anak Agung, siapa sih yang berani dengan beliau".

Diceritakan sekarang ia akan menjadi abdi di puri. Suatu hari, para abdi dan pengikut Ida Anak Agung datang menghaturkan bhakti ke hadapan beliau. Penuh sesak di halaman puri ketika Tjai Tjenik mengintip dari pintu puri dan ia melihat ada banyak orang. Disanalah muncul rasa takutnya, lalu ia berteriak meminta pertolongan. Datanglah seorang ajudan bertanya kepada Tjai Tjenik. Tjai Tjenik berkata kalau ia takut, dan iapun menceritakan pesan ayahnya. Setelah selesai bercerita, ajudan itu berkta: "nah kalau begitu, kamu pergi kesana, lurus ke arah timur saja, pasti kamu selamat". Setelah ajudan itu berkata demikian, lalu Tjai Tjenik pergi meninggalkan puri.

Sekarang diceritakan perjalanan Tjai Tjenik, ia sudah tiba di sebuah hutan lebat, lalu ia melihat seekor macan akan memangsa babi. Lalu ia mulai berpikir: "Nah ini dia, mungkin ini yang dikatakan ditakuti oleh orang banyak, akan aku cari ia kesana."

Diceritakan sekarang Si Macan yang baru saja akan memangsa babi lalu dipukul oleh Tjai Tjenik. Si Macan kaget dan menoleh ke arahnya. Setelah mengetahui bahwa yang datang adalah seorang manusia, ia lalu berkata: "Ih Tjai Tjenik, mengapa kamu ke tengah hutan seorang diri seperti ini?" Pulang sana!nanti aku makan kamu”. Tjai Tjenik menjawab: "ah, aku tidak mau pulang". Berulang kali Si Macan mengusirnya tapi ia tetap teguh pada pendiriannya tidak mau pergi. Si Macan lalu pergi dan diikuti oleh Tjai Tjenik.

Setelah melewati perjalanan yang jauh, mereka berdua melihat sebuah padukuhan (pasraman). Si Macan lalu memanggil Djero Dukuh: "Djero Dukuh, Djero Dukuh". "Siapa itu yang berteriakteriak?" tanya Djero Dukuh. "Saya Si Macan", lalu Djero Dukuh keluar dan bertanya kepada Si Macan. Hei Macan, mengapa tumben kamu datang kesini?" Si Macan berkata: "begini Dukuh, ini ada anak kecil mengikuti saya kemana-mana. Kemanapun saya pergi dia mengikuti, sampai-sampai saya tidak dapat makanan, binatang buruan saya lari semuanya karena ulahnya. Disuruh pulang juga ia tidak mau, sekarang Djero Dukuh saja yang mengajak dia tinggal disini”, kata Si Macan. "ya jika memang itu keinginanmu, biar aku saja yang mengajaknya tinggal disini. Lalu Si Macan memanggil Tjai Tjenik dan berkata: "Tjai Tjenik, sekarang kamu tinggal disini saja bersama Djero Dukuh. Apapun perkataan Djero Dukuh ikuti saja. Jangan kamu tidak mengikuti!"'Ya!" begitu jawaban Tjai Tjenik, lalu Si Macan pergi.

Sekarang diceritakan Tjai Tjenik mengabdi di kediaman Djero Dukuh. Suatu hari, Djero Dukuh bertanya kepada Tjai Tjenik: "Tjai Tjenik, siapa namamu dan dimana rumahmu?". Tjai Tjenik ingat akan pesan dari Si Macan untuk mengikuti semua perkataan Djero Dukuh, lalu ia berkata: "Tjai Tjenik, siapa namamu dan dimana rumahmu?'Djero Dukuh bingung melihat tingkah Tjai Tjenik dan berkata 
dalam hati: "Ah mungkin dia memang begitu, suka meniru saja.”

Ketika Djero Dukuh akan melakukan puja kehadapan Tuhan, Tjai Tjenik disuruh mengambil pasepan (wadah untuk membakar dupa, kayu cendana) serta pawacikan (wadah pembersihan tangan dan kaki). Begini kata beliau: "Tjai Tjenik, ambilkan saya pasepan dan pawacikan". Tjai Tjenik lalu mengikuti perkataan Djero Dukuh: "Tjai Tjenik, ambilkan saya pasepan dan pawacikan". Kemudian setelah Djero Dukuh siap-siap melakukan puja, beliau duduk di bale pamujan (tempat melakukan puja). Tjai Tjenik duduk di bawah. Djero Dukuh mengambil Genta, dan Tjai Tjenik mengambi kayu untuk mengikuti Djero Dukuh. Djero Dukuh membuang bunga, Tjai Tjenik menggunakan sisa-sisa bunga dan dibuang. Tjai Tjenik selalu begitu disana namun Djero Dukuh tidak pernah memarahinya.

Sekarang Tjai Tjenik sudah semakin dewasa dan semakin pintar. Djero Dukuh lalu berbicara kepada istrinya. "Istriku, kalau Tjai Tjenik disini, lamalama aku akan dikalahkan, akan dibinasakan. Sekarang ayo kita bodohi dia, biar dia mati". Kalau dibiarkan hidup, sulit rasanya saya". Istrinya berkata: "ya jika memang begitu keinginan djero". Daripada djero yang dibunuh, lebih baik dia saja yang dibunuh". Lalu sekarang bagaimana? Apa yang harus dilakukan?"Ah, bingung juga aku memikirkan hal ini istriku."

Setelah itu, Djero Dukuh memanggil Tjai Tjenik dan berkata: "Tjai
Tjenik, sekarang kamu kan sudah dewasa, kamu tidak menjenguk ayah ibumu?"

Tjai Tjenik berkata: "ya djero, kalau tentang kerinduan saya dengan ayah dan ibu saya memang sudah sangat rindu sekali. Apalagi saya tidak mengenal ibu saya sama sekali, karena sejak kecil saya sudah ditinggal mati oleh ibu saya. Lalu sekarang bagaimana caranya, ingin melihat orang yang sudah mati?". Djero Dukuh lalu berkata:"Ah itu sih mudah sekali”.

Diceritakan di dekat rumah Djero Dukuh ada serumpun bambu, dan ada satu batang yang paling tinggi, dan ujung bambunya agak tersembunyi. Itu yang ditunjukkan oleh Djero Dukuh. "Tjai Tjenik, coba lihat bambu yang paling tinggi itu. Kalau kamu ingin bertemu dengan orangtuamu, naiklah ke pohon bambu itu, pasti kamu akan bertemu dengan ayah ibumu". Karena terlalu gembira akan bertemu dengan ayah ibunya, hingga ia tidak tahu kalau dirinya diperdaya, ia lalu buru-buru menaiki pohon bambu itu. Diceritakan ia sudah sampai di bagian tengah pohon bambu itu, ia lalu berteriak: "Djero Dukuh, Djero Dukuh, kenapa saya belum bertemu juga dengan orangtua saya?" Djero Dukuh yang berada di bawah berkata:'Naik lebih tinggi lagi, pasti kamu akan bertemu". Mendengar hal itu, Tjai Tjenik melanjutkan untuk menaiki bambu itu. Ia sudah naik cukup tinggi, dan Djero Dukuh terlihat kecil, lalu Ia kembali memanggilmanggil Djero Dukuh. "Djero Dukuh, Djero Dukuh, kenapa saya belum bertemu juga dengan orangtua saya?" Djero Dukuh 
berkata: "kamu cerewet sekali, pokoknya naik saja terus, sedikit lagi pasti kamu bertemu dengan orangtuamu!'Hingga tinggal sejengkal lagi dari ujung pohon bambu itu, Tjai Tjenik belum juga melihat dan bertemu dengan siapapun, hingga akhirnya badannya mulai bergoyang, ia berusaha keras mencapai puncak pohon bambu itu, dan sesampainya dipuncak, ia lalu menghilang.

Dikisahkan memang karena takdir Tuhan, Tjai Tjenik sampai di alam sana, dan bertemu dengan kedua orangtuanya. Sekarang diceritakan Djero Dukuh melihat ke atas, ia tidak melihat Tjai Tjenik." Ia bertanya-tanya, "kemana perginya Tjai Tjenik, kalau jatuh, kenapa tidak ada suara benda jatuh. Wah pintar juga anak itu, akan aku naiki pohon bambu itu, biar aku tau ia pergi kemana". Djero Dukuh lalu menaiki pohon bambu itu.

Diceritakan bahwa Djero Dukuh sudah sampai di pertengahan, tapi belum melihat siapapun, ia memutuskan untuk naik lagi. Saat ia akan menggapai ujung pohon bambu, patahlah pohon bambu itu, dan pantatnya tertusuk bambu, hingga darahnya bercecerah mengalir di pohon bambu itu. Djero Dukuh akhirnya tewas karena kesalahannya sendiri.

Begitulah ceritanya, sejarah adanya pohon bambu tultul, dan tidak boleh dibawa ke sanggah (tempat suci di rumah tangga keluarga Hindu ).

\subsection{Nilai Hedonis (kesenangan atau hiburan)}

Setiap karya sastra memberikan kesan personal kepada pembacanya. Seorang peminat sastra sering merasa terhibur oleh alur cerita maupun isi dari karya sastra yang dibaca. Demikian pula halnya dengan Satua Tjai Tjenik ini. Berikut beberapa kutipan satua ini yang memberikan hiburan bagi pembacanya:

"Katjarita djani $i$ matjan, mara ia ukana njarap i tjeleng, lantas ketigina teken Tjai Tjenik. Tangkedjut lantas $i$ matjan, laut ia matolihan. Mara nota ada djelma teka, laut ia ngomong ; "Ih Tjai Tjenik, ngenken tjai mai tjelapat-tjelapat padidian katengah alase?" Keme mulih me, njanan kamah tendasne”. Masaut Tjai Tjenik : “Ah, awak sing njak mulih". Ping kuda-kuda kaden suba Tjai Tjenik tundungina teken i matjan, masih ia tusing njak magedi. I matjan lantas ngalautang padjalanne, tur tutuga teken Tjai Tjenik."

"Saat Si Macan hendak menangkap seekor babi, disana Tjai Tjenik memukulnya. Hal ini dapat dikatakan cukup menghibur, karena jarang ada manusia yang berani melakukan tindakan seperti itu, Tjai Tjenik menganggap Macan adalah binatang biasa padahal ia seekor binatang buas. “6

Nilai hiburan lainnya ketika Si Macan berbicara dengan Tjai Tjenik dan mengusirnya, tetapi Tjai Tjenik justru cuek dan saat $\mathrm{Si}$ Macan pergi meninggalkannya, Tjai Tjenik justru mengikutinya pergi. Hal ini nampak seperti keluguan dan kekonyolan seorang anak yang tidak takut justru kepada seekor binatang buas sekalipun, bahkan ia malah mengikutinya kemanapun ia pergi." 
Demikian pula ketika Tjai Tjenik mengikuti setiap perkataan dan prilaku dari Djero Dukuh seperti kutipan berikut:

"Katjarita djani Tjai Tjenik ditu ia mamarekan sig djero Dukuhe. Sedek dina anu matakon kone djero Dukuh teken Tjai Tjenik: "Tjai Tjenik, njen adan tjaine, muah didja umahe?" Tjai Tjenik inget ia teken pabesen $i$ matjane, nunden nuutang dogen pangandikan djero Dukuhe, lantas ia masaut : "Ih Tjai Tjenik, njen adan tjaine muah didja umahe?” Makajunkajun lantas djero Dukuh : "Ah,kamulan djenenga ia keto, nuut nuutang dogen.Sedek djero Dukuh maweda, Tjai Tjenik nikaanga njemak pasepan teken pawadjikan. Kene pangandikanne ; “Tjai Tjenik, djemakang awake pasepane teken pawadjikane!" Tjai Tjenik nuutang kone pangadikan djero Dukuhe buka keto : "Tjai Tjenik, djemakang awake pasepane teken pawadjikane!"

Tjai Tjenik diminta untuk mengikuti perkataan atau perintah Djero Dukuh oleh Si Macan, namun ia justru menyalah artikannya. Ia meniru (mengikuti) semua kata-kata Djero Dukuh.

Tingkah laku Tjai Tjenik yang lugu ini dapat memberi hiburan bagi pembaca yang tergelitik membayangkan bahwa justru tidak ada perintah yang dapat dilaksanakan oleh Tjai Tjenik, karena ia hanya meniru perkataan Djero Dukuh bukan mendengarkan dan menjalankan perintahnya. Namun dibalik itu, tersirat makna yang dalam tentang bentuk pengabdian kepada orangtua, meskipun Djero Dukuh bukan orangtua kandungnya.

\subsection{Pendidikan Agama Hindu dalam Satua Tjai Tjenik}

\subsubsection{Guru Susrusa}

Guru Susrusa dalam ajaran Panca Nyama Brata berarti berbakti kepada guru atau mendengarkan dan menaruh perhatian terhadap nasihat guru (Suhardana, 2007: 9). Umat Hindu diajarkan untuk selalu berbakti kepada Catur Guru.

Palguna (2011: 72) menjelaskan bahwa Guru berarti berat, yang berat adalah Jnana-nya. Guru Swadyaya ditujukan kepada Ida Sang Hyang Widhi Wasa; Guru Pengajian untuk yang mengajarkan ilmu pengetahuan; dan Guru Rupaka atau Guru Reka untuk yang memberikan kehidupan tubuh, yaitu orangtua. Sedangkan Guru Wisesa adalah pemerintah. Dimasukkannya pemerintah sebagai Guru pertanda politik sudah memasuki agama. Dalam konsep Tri Guru pemerintah tidak termasuk. Istilah Tri Guru tergeser oleh Catur Guru. Pergeseran terjadi ketika agama tidak lagi semata urusan spiritual. Namun demikian, dalam satua Tjai Tjenik ini, yang ditekankan adalah tentang penghormatan kepada Guru Rupaka atau Guru Reka.

Tjai Tjenik menaruh rasa bakti kepada Djero Dukuh yang sudah dianggap orangtua baginya. Dirinya sangat menaruh hormat kepada Djero Dukuh tersebut, bahkan ketika ia diperdaya, ia tidak menyadarinya karena ia berpikir Djero 
Dukuh mengajarkan hal yang benar. Lebih jelasnya pada kutipan berikut:

"Tjai Tjenik, tingalin dja tiinge ane paling tegeha ento. Lamun tjai makeneh apang nepukin raraman tjaine, tiinge ento penek to, tepbaan tjai ngalih meme bapan tjaine”. Baan legan kenehne Tjai Tjenik, lakar nepukin rarama tuara naan teken dewek kabelog-belog, ngenggalang lantas ia menek tiinge ento."

Tjai Tjenik mengikuti perintah Djero Dukuh untuk naik ke atas pohon bambu yang tinggi agar ia dapat bertemu dengan orangtuanya yang sudah tiada. Ia tidak mengetahui bahwa dirinya diperdaya oleh Djero Dukuh. Karena baktinya kepada Guru Rupaka, ia menuruti perintah Djero Dukuh hingga akhirnya ia menghilang di ujung bambu yang dinaiki.

Demikianlah hendaknya seorang anak agar senantiasa berbakti kepada orangtuanya karena pengabdian kepada orangtua sama dengan melayani Tuhan. Terkait dengan hal ini, Saraswati (2009: 251) menyatakan bahwa dalam Upanisad disebutkan "Matru Devo Bhava", "Pitra Devo Bhava" yang artinya hormati ibu sebagai dewi agung, dan hormati ayah sebagai dewa agung. Demikian kata Veda, dan perintah tersebut digambarkan dalam bakti Tjai Tjenik kepada Djero Dukuh dengan mentaati perintahnya. Lebih lanjut menurut Titib, 203: 127), seorang anak yang memiliki budhi pekerti yang luhur senantiasa menunjukkan sikap dan prilaku yang membahagiakan orangtua dan keluarganya.

\subsubsection{Karma}

Kata Karma berasal dari bahasa Sanskerta yaitu ' $k r$ ' yang artinya "berbuat". Semua perbuatan adalah karma. Setiap saat manusia melakukan karma. Ketika berbicara, manusia melakukan karma, setiap bernafas, itu adalah karma, berjalan, berpikir, itu juga karma. Semua yang manusia lakukan, baik fisik maupun mental adalah karma, dan karma itu meninggalkan kesan atau bekas dalam diri mausia (Vivekananda, 2001: 132)

$\begin{array}{rrr}\text { Terminologi } & \text { karma } & \text { sering } \\ \text { dikaitkan dengan } & \text { Karmaphala } & \text { yang }\end{array}$ berarti hasil dari perbuatan. Karmaphala telah menjadi bagian dari keyakinan Umat Hindu yang akan berpengaruh kepada kelahiran kembali (punarbhava). Penyebab yang baik, akan mendatangkan akibat yang baik. Karmaphala terbagi ke dalam tiga bagian sesuai dengan jenis karmaphala yang diperoleh. Netra (2009: 29) menjelaskan jenis-jenis karmaphala dimaksud yaitu: Sancita karmaphala (hasil yang diterima saat ini akibat perbuatan sebelumnya), Prarabdha Karmaphala (perbuatan yang dilakukan saat ini dan hasilnya juga diterima saat ini), dan Kryamana Karmaphala (perbuatan yang dilakukan saat ini, phalanya akan dinikmati di kehidupan selanjutnya).

Hukum karmaphala ini bersifat adil dan universal tanpa memandang status sosial seseorang, karma juga adalah teman yang paling setia dalam hidup manusia seperti yang dinyatakan dalam Sarasamuccaya 32 sebagai berikut: 
"Apanikang kadang warga rakwa, ring tunwan hingan pangateraken, kunang ikang tumut, sahayanikang dadi hyang ring paran, gawenya subhaasubha juga, matangnyan prihena tiking gawe hayu, sahayanta anuntunakena ri pona dlaaha"

Artinya:

"Karena kaum kerabat itu hanya sampai di tempat pembakaran (kuburan) batasnya mereka itu mengantarkan. Adapun yang turut menemani sang roh di akherat adalah perbuatannya yang baik, ataupun yang buruk saja, oleh karena itu hendaklah diusahakan berbuat baik, yaitu teman anda yang menjadi pengantar ke akherat kelak"

Satua Tjai Tjenik ini secara implisit mengajarkan umat untuk selalu berkarma yang baik tanpa terikat kepada hasil yang akan diperoleh. Meskipun Tjai Tjenik berkeinginan untuk bertemu dengan kedua orangtuanya, namun karena dia menjalankan perintah Djero Dukuh tanpa penolakan dan dengan bersungguhsungguh, iapun akhirnya dapat bertemu dengan kedua orangtuanya. Meskipun nampak tidak masuk akal, namun itu adalah cerminan dari pendidikan tentang filsafat Karma Yoga yang dalam Bhagavadgita disimpulkan sebagai bekerja tanpa motif, bekerja dengan penuh konsentrasi dan mencintai pekerjaan atau hal yang dilakukan. Salah satu slokanya berbunyi sebagai berikut:

"niyatam kuru karma tvam
Karma jyayo hyakarmanah

Sarira-yatrapi ca te na

Prasiddhyed akarmanah."

Artinya:

"Bekerjalah seperti yang telah ditentukan, sebab berbuat lebih baik daripada tidak berbuat, dan bahkan tubuhpun tak akan berhasil terpelihara tanpa berkarya."

Sosok Tjai Tjenik dengan penuh keyakinan menaiki pohon bambu agar bisa bertemu dengan ayah ibunya yang telah lama meninggal. Ia melakukan itu karena perintah Djero Dukuh yang memperdayanya agar Tjai Tjenik tidak bisa mengalahkan kepandaian dari Djero Dukuh. Namun pada akhirnya karena keyakinannya yang kuat, Tjai Tjenik berhasil mencapai puncak bambu itu dan menuju nirwana bertemu kedua orangtuanya, sedangkan Djero Dukuh yang licik itu ikut memanjat bambu tadi guna mencari Tjai Tjenik yang tiba-tiba menghilang dan akhirnya ia mati tertusuk bambu yang dipanjat. Dari satua itu kita juga diajarkan untuk meyakini kebenaran akan keberadaan kekuatan di luar kekuatan manusia yang sanggup menyelamatkan manusia dari hal-hal buruk yang dialaminya.

Prilaku Djero Dukuh mengajaran bahwa setiap perbuatan baik ataupun buruk akan mendatangkan hasil yang sesuai. Tindakannya yang menipu Tjai Tjenik menampilkan contoh ajaran Prarabdha Karmaphala, karena ia sudah berbuat saat itu dan mendapatkan hasilnya saat itu juga. Generasi muda Hindu dalam hal ini diharapkan tidak hanya cerdas 
secara intelektual, namun juga cerdas secara spiritual dan emosianal.

\subsubsection{Catur Paramita}

Catur Paramita secara etimologi berarti empat perwujudan budhi pekerti yang luhur. Sejalan dengan yang dinyatakan Subagiasta (2007:11) bahwa Catur Paramita adalah empat jenis perilaku manusia yang luhur dan mulia meliputi: 1) Maitri yang berarti kelembutan dalam bergaul atau persahabatan, 2) Karuna yang berarti berprilaku penuh belas kasihan, 3) Mudita artinya dapat berperilaku ceria, gembira serta bahagia, dan 4) Upeksa sikap yang mulia untuk menghargai dan menghormati mahkluk lainnya.

Ajaran Catur Paramita secara implisit terdapat dalam beberapa kutipan satua Tjai Tjenik yang telah dipaparkan. Contoh prilaku yang mendekati ajaran Maitri ketika Tjai Tjenik menanyakan tempat yang paling aman untuk tinggal, dan seorang ajudan raja memberikannya petunjuk untuk pergi lurus ke arah timur saja, pasti dirinya akan selamat. Ajaran Maitri lainnya ketika $\mathrm{Si}$ Macan mengantarkan Tjai Tjenik menemui Djero Dukuh di rumahnya. Percakapan antara Djero Dukuh dan Si Macan menunjukkan persahabatan yang terjalin dengan baik.

Demikian pula ajaran Karuna ditunjukkan oleh sosok Djero Dukuh ketika mulai merawat dan membesarkan Tjai Tjenik, namun karena pengaruh pikiran buruk yang menyelimutinya, ia justru memperdaya Tjai Tjenik setelah beranjak dewasa dan merasa tersaingi.
Ajaran Mudita juga banyak ditampilkan oleh Tjai Tjenik. Meskipun ia kehilangan kedua orangtuanya, ia menunjukkan keceriaan, misal ketika bertemu dengan Si Macan, ia justru bermain-main dengannya, kemudian ketika sudah berada di rumah Djero Dukuh, Tjai Tjenik dikisahkan pribadi yang ceria dan lugu seakan tidak memiliki permasalahan hidup yang mungkin saja tidak semua orang bisa melakukan hal yang sama.

Ajaran Upeksa ditunjukkan baik oleh Si Macan maupun Djero Dukuh yang saling menghargai. Si Macan juga menghargai Tjai Tjenik karena ia tidak memakannya, justru mengantarkannya ke rumah Djero Dukuh untuk dirawat dan dibesarkan.

Satua Tjai Tjenik ini dapat memberikan renungan bagi umat manusia di jaman Kali ini. Setiap permasalahan pasti ada pemecahannya. Demikian pula sikap saling menghargai dan membantu sesama hendaknya dijadikan sebagai kewajiban, bukan sebuah tindakan yang mengharapkan pujian.Upanisad dalam Mahavakya (kata-kata yang agung)nya telah mengajarkan untuk memandang sama terhadap semua mahkluk, karena terdapat jiwa yang agung bersemayam dalam diri setiap mahkluk. Menolong sesama tanpa membedakan Suku, Agama, Ras maupun Golongan diupayakan menjadi sebuah tuntutan moral sebagai umat manusia yang dibekali dengan akal dan pikiran. Manava seva, Madhava seva (Melayani manusia, sama dengan melayani Tuhan). 
Generasi muda Hindu dewasa ini dihadapkan pada konflik-konflik bernuansa SARA, dan dengan memahami nilai-nilai dalam satua ini minimal dapat membangkitkan rasa persaudaraaan dan sikap tolong menolong kepada sesama tanpa membedakan latar belakangnya.

\subsubsection{Dama}

Kata Dama berarti menundukkan nafsu, mengendalikan nafsu. Dama juga diartikan mengendalikan diri atau mengendalikan nafsu (Suhardana, 2007: 13).

Ajaran Dama dalam satua ini ditunjukkan oleh Si Macan yang hendak memakan Tjai Tjenik namun dia mampu menahan dirinya dan justru membantu Tjai Tjenik keluar dari hutan dan menemui Djero Dukuh. Manusia diajarkan untuk belajar dari satua-satua yang sering disimbolkan oleh prilaku binatang, karena memang satua sendiri berasal dari kata Sato yang artinya binatang. Satua juga merupakan refleksi dari kehidupan manusia itu sendiri.

Umat Hindu dalam hal ini generasi muda hendaknya senantiasa mampu mengendalikan diri dan nafsunya agar dapat menjalankan swadharmanya (kewajibannya) dengan baik dan tidak melenceng dari dharma itu sendiri.

\subsubsection{Arjawa}

Kata Arjawa berasal dari kata "Arja" yang berarti teguh pendirian. Arjawa juga berarti mempertahankan kebenaran. Orang yang melakukan Arjawa Brata adalah orang yang teguh dan berdisiplin sehingga tidak mudah diombang-ambingkan oleh pikiran yang tidak baik dan tidak suci (Suhardana, 2007: 14).

Ajaran arjawa ini ditunjukkan oleh Tjai Tjenik yang teguh kepada pendiriannya untuk mencari tempat yang aman, dan tidak takut kepada ancaman $\mathrm{Si}$ Macan yang akan memakannya hingga ia akhirnya berhasil mengunjungi tempat yang aman yakni kediaman Djero Dukuh. Lebih jelasnya seperti kutipan berikut ini: Katjarita djani $i$ matjan, mara ia ukana njarap i tjeleng, lantas ketigina teken Tjai Tjenik. Tangkedjut lantas $i$ matjan, laut ia matolihan. Mara nota ada djelma teka, laut ia ngomong ; "Ih Tjai Tjenik, ngenken tjai mai tjelapat-tjelapat padidian katengah alase?" Keme mulih me, njanan kamah tendasne”. Masaut Tjai Tjenik : "Ah, awak sing njak mulih". Ping kuda-kuda kaden suba Tjai Tjenik tundungina teken i matjan, masih ia tusing njak magedi. I matjan lantas ngalautang padjalanne, tur tutuga teken Tjai Tjenik.

$\mathrm{Si}$ Macan sudah berusaha mengusir Tjai Tjenik dari hutan namun ia tetap pada pendiriannya untuk menuju tempat yang aman.

Generasi muda Hindu hendaknya meniru prilaku Tjai Tjenik agar selalu teguh pada pendirian tanpa khawatir akan resiko yang akan dihadapi dan tidak mudah terombang-ambing. Tentu pendirian yang berdasarkan atas dharma 


\section{PENUTUP}

Satua Tjai Tjenik merupakan salah satu dari sekian banyak satua yang hidup di Bali. Satua menurut fungsinya dapat dijadikan sebagai media pendidikan agama Hindu. Satua Tjai Tjenik secara implisit mengajarkan tentang pendidikan agama Hindu seperti Guru Susrusa, Karma, Catur Paramita, Dama dan Arjawa. Analisis terhadap satua-satua lainnya perlu dikembangkan agar minat baca serta pendalaman ajaran agama Hindu semakin tumbuh dan berkembang sehingga tercipta generasi muda Hindu yang religius dan berkarakter mulia.

\section{DAFTAR PUSTAKA}

Anonim. Tt. Satua-satua Bali. Widya Wahana Library Collection

Kajeng, I Nyoman, dkk. 1997. Sarasamuccaya dengan Teks Bahasa Sanskerta dan Jawa Kuno. Surabaya: Paramita.

Netra, Anak Agung Gde Oka. 2009.

Tuntunan Dasar Agama Hindu. Denpasar: Widya Dharma.

Palguna, IBM Made. 2011. Leksikon Hindu. Mataram: Sadampaty Aksara.

Pudja, Gde. 2003. Bhagavadgita (Pancama Weda). Jakarta: Pustaka Mitra Jaya

Rampan, Korrie Layun. 2014. Teknik Menulis Cerita Rakyat. Bandung: Yrama Widya.

Saraswati, Sri Chandrasekharendra. 2009. Peta Jalan Veda. Jakarta: Media Hindu.

Suastika, I Made. 2011. Tradisi Sastra Lisan (Satua) di Bali. Kajian
Bentuk, Fungsi, dan Makna. Denpasar: Pustaka Larasan.

Subagiasta, I Ketut. 2007. Etika Pendidikan Agama Hindu. Surabaya: Paramita

Suhardana, K.M 2007. Yama Niyama Brata. Surabaya: Paramita.

Titib, I 2003. Menumbuhkembangkan

Pendidikan Budhi Pekerti pada Anak (Perspektif Hindu). Jakarta: Ganeca Exact.

Vivekananda, Svami. 2001. Vedanta Gema Kebebasan. Surabaya: Paramita. 